\title{
Representação social da pesquisa e da atividade científica: um estudo com doutorandos
}

\author{
Edna Maria Querido de Oliveira Chamon \\ Universidade de Taubaté
}

\begin{abstract}
Resumo
Este trabalho analisa os processos e conteúdos representacionais de doutorandos na área de ciências exatas com relação à pesquisa. Para isso, foram realizadas 26 entrevistas com alunos de diversas áreas das ciências exatas. Uma análise de conteúdo informatizada dessas entrevistas revelou uma classe de discursos ligada ao tema pesquisa, com uma nítida separação entre pesquisa fundamental e aplicada, além de considerações éticas sobre o "bom" e "mau" uso dos produtos da ciência e a responsabilidade do pesquisador com respeito a esse uso. Foi possível identificar nesse caso os processos psicossociais de objetivação e ancoragem, que estão na gênese da representação social da pesquisa.

Palavras-chave: representação social; doutorandos; representação da pesquisa
\end{abstract}

\begin{abstract}
Social representation of research and scientific activity: a study with PhD students. This paper analyzes the social representation of the concept of research constructed by students enrolled in a doctoral program. The social representation was obtained from the content analysis of a set of 26 interviews. This analysis showed a separation between basic and applied research, the presence of ethic notions about "good" and "bad" use of science findings and the researcher responsibility of this use. We were able to identify the basic processes that generate the social representation of research for this group.
\end{abstract}

Keywords: social representation; PhD students; research representation

A s sociedades modernas têm grande consideração pela ciência. Ela é, entre outras atividades sociais e culturais, uma produção das sociedades sobre si mesmas. A ciência consiste num esforço (individual e coletivo) para substituir, por um modelo explicativo, o caos que nos rodeia. Mas também é a ciência dos produtos acabados, uma ciência feita e que, num certo sentido, já pertence ao passado.

Uma outra face, menos conhecida, é aquela que corresponde ao trabalho quotidiano dos laboratórios, que é chamada pesqui$s a$. A atividade de pesquisa evolui num contexto bem diferente daquele da ciência acabada. Ali encontramos os fracassos, os estudos que não foram concluídos, os problemas de financiamento, as disputas sobre a primazia dos resultados e várias outras situações que, em princípio, seriam caracterizadas como "não-científicas", mas que na prática não podem ser dissociadas do trabalho de um pesquisador.

O objetivo deste trabalho é o estudo dessas situações e, mais precisamente, a forma como os doutorandos as percebem. $\mathrm{Na}$ verdade, os doutorandos são pesquisadores em formação e seu trabalho é tanto construção científica quanto identitária. Eles conhecem, como todo mundo, o universo da ciência acabada; eles descobrem, na prática da pesquisa, a ciência tal como ela é feita.

Este estudo tem por fundamento a psicologia social e, particularmente, a teoria das representações sociais. Estudamos aqui as crenças e opiniões dos doutorandos a respeito da pesquisa, fora de um contexto puramente científico. Em outras palavras, nós procuramos caracterizar a pesquisa como objeto de representação social para esse grupo de pesquisadores em formação. Nosso interesse é observar como essa representação continua a funcionar durante a atividade científica e como pode dirigir essa atividade ao mesmo tempo em que é modificada por ela.

Este trabalho procura mostrar que existe uma continuidade na representação da atividade científica e que os esquemas do senso comum continuam a influenciar os doutorandos em seu trabalho de pesquisa.

Nós nos concentramos na análise de como os doutorandos vêem a distinção entre pesquisa fundamental e pesquisa aplicada e de como eles percebem as relações entre a ciência e a sociedade. Para isso, entrevistamos um grupo de doutorandos na área de ciências exatas e procedemos a uma análise de conteúdo dessas entrevistas. Os resultados obtidos com essa análise são 
apresentados a seguir.

No desenvolvimento deste trabalho, um certo número de conceitos e de sistemas de explicação nos pareceram necessários para fornecer, no início, uma direção ao estudo realizado e, no final, um suporte explicativo para os resultados obtidos. Esta seção expõe as teorias nas quais nos apoiamos para esse desenvolvimento. A apresentação será necessariamente breve e incompleta. Nosso objetivo é principalmente fazer um levantamento do que nos pareceu essencial, mostrando as escolhas que fizemos ao longo do caminho e os conceitos-chave que serviram para a construção deste estudo.

Duas áreas em particular serão abordadas. Primeiramente, a das representações sociais. Apresentamos apenas um esboço dos processos que definem a dinâmica das representações sociais: a objetivação e a ancoragem. Pretendemos simplesmente explicitar nossa filiação à teoria do campo estruturado, tal como ela é desenvolvida pelos pesquisadores da escola de Genebra ou de Paris. A teoria do núcleo central não será abordada neste trabalho.

Um segundo tema importante nesta pesquisa engloba as diferentes teorias que existem para o estudo da ciência. Comparamos, de maneira simplificada, as abordagens propostas pela epistemologia e pela sociologia da ciência, e discutimos quais as possíveis contribuições da psicologia social para a discussão desse tema.

\section{Análise dinâmica das representações sociais}

As representações sociais se apresentam sempre sob dois aspectos: o da imagem (reprodução do real de maneira concreta) e o do conceito (abstração do sentido do real, significação que corresponde à imagem do real). Para compreender a dinâmica das representações sociais é preciso analisar os dois processos que intervêm na sua formação: a objetivação e a ancoragem. Esses processos "indicam a maneira como o social transforma um conhecimento em representação e como esta representação transforma o social" (Jodelet, 1992, p. 367). Eles mostram uma das funções de base das representações sociais: a integração do novo, do inesperado e do inexplicável.

\section{O conceito de objetivação}

A objetivação é o processo que torna concreto o que é abstrato, que materializa a palavra, que transforma o conceito em objeto e os torna intercambiáveis. Na realidade, ela substitui o conceito pelo que é percebido, o objeto pela sua imagem, a imagem tornando-se o objeto e não sua representação. A imagem é sempre uma simplificação, necessariamente deformada, do conceito que lhe deu origem.

A objetivação gera a opacidade da representação social. Uma representação social é opaca a si mesma, isto é, ela não se coloca no discurso como representação. Ela é vista como forma de verdade, como observa Rouquette (1994): “A maior parte do tempo, cada um está convencido de que fala da realidade das coisas, quando apenas exprime sua própria compreensão daquilo que percebe" (p. 172).

Uma das funções da objetivação é de facilitar a comunicação, embora isso se faça pela dissociação do objeto ou do conceito do quadro científico ou ideológico que lhe dá sentido.
Uma outra função, ligada à anterior e talvez mais fundamental, é a de caracterizar uma inscrição psicossocial (Rouquette, 1994, p. 183). O objeto apropriado pelo grupo não se distingue da representação deste objeto. Não existe o sentimento de arbitrário ou relativo com respeito à representação do objeto. A imagem torna-se o objeto.

\section{$O$ conceito de ancoragem}

O processo de ancoragem diz respeito ao enraizamento social da representação. Sua função é de realizar a integração cognitiva do objeto representado num sistema de pensamento preexistente. Dessa maneira, os novos elementos de conhecimento são colocados numa rede de categorias mais familiares. O sistema de classificação utilizado supõe uma base de representação partilhada coletivamente (Jodelet, 1992, p. 377), isto é, categorias socialmente estabelecidas. Pode-se dizer que o grupo exprime sua identidade a partir do sentido que ele dá à representação.

Assim, a ancoragem se refere a significações distintas daquelas internas ao conteúdo de uma representação. São as significações que intervêm nas relações simbólicas existentes no grupo social que representa o objeto.

Willem Doise (1992, p. 189) propõe uma análise da ancoragem das representações sociais a partir de uma classificação em três modalidades: (1) a ancoragem do tipo psicológico diz respeito às crenças ou valores gerais que podem organizar as relações simbólicas com o outro; (2) a ancoragem do tipo psicossociológico inscreve os conteúdos das representações sociais na maneira como os indivíduos se situam simbolicamente nas relações sociais e nas divisões posicionais e categoriais próprias a um campo social definido; e (3) a ancoragem do tipo sociológico refere-se à maneira como as relações simbólicas entre grupos intervêm na apropriação do objeto.

Esses dois processos, objetivação e ancoragem, são complementares, ainda que aparentemente opostos: um busca criar verdades óbvias para todos e independentes de todo determinismo social e psicológico enquanto o outro, ao contrário, refere-se à intervenção de tais determinismos na gênese e transformação dessas verdades. O primeiro cria a realidade em si, o segundo lhe dá significação.

A representação social estabelecida por esses processos garante uma certa estabilidade epistemológica ao objeto representado. O mundo se modifica mais depressa do que a idéia que fazemos dele. Transformando o complexo em simples (objetivação) e o estranho em familiar (ancoragem) ela permite uma integração "suave" do novo e do desconhecido.

É justamente essa propriedade de estabilidade que vai garantir uma continuidade na representação da atividade científica (Doise, 1990). Mas estabilidade não significa rigidez, e continuidade não implica determinação. Assim, as representações sociais vão evoluir, tornar-se específicas, mas manterão, como veremos na análise de nossos resultados, suas características fundamentais iniciais.

\section{A construção da ciência}

Se nós considerarmos a ciência como objeto de estudo, duas abordagens mais ou menos independentes são propostas atual- 
mente: a abordagem epistemológica e a abordagem sociológica. Nós gostaríamos, neste trabalho, de acrescentar a essas duas a da psicologia social e, mais precisamente, a das representações sociais da pesquisa. Essa última procura explicitar as representações que certos grupos - o público em geral, os políticos, a comunidade científica ou outros - têm da pesquisa, e as relações entre essas representações e as práticas sociais desses grupos. De fato, como sugere Barreau (1995), os "esquemas do conhecimento comum não deixam de habitar o espírito dos cientistas, não apenas em sua vida privada, o que é óbvio, mas também no seu próprio trabalho de pesquisa" (pp. 12-13). Essa posição é reforçada por Doise que defende, como já mencionamos, uma continuidade na representação da atividade científica.

Nós tentaremos aqui apresentar de maneira sucinta as características de cada uma dessas abordagens e a contribuição que a psicologia social pode trazer para essa discussão.

\section{A abordagem epistemológica}

A filosofia da ciência é a mais antiga das modalidades de estudo da ciência. Vários filósofos se debruçaram sobre o problema de pensar a ciência, no que ela consiste, como ela funciona. Se tivéssemos de apontar apenas dois desses pensadores, que exerceram maior influência sobre os rumos dessa disciplina, seguramente nossa escolha recairia sobre Karl Popper e Thomas Kuhn.

Popper desenvolve a idéia de que o empirismo - baseado nas observações - não é capaz de obter enunciados de caráter universal. Ele propõe uma definição, hoje clássica, de enunciado científico apoiada no conceito de falseabilidade: uma teoria é científica na medida em que ela é capaz de gerar enunciados que podem ser desmentidos pela experimentação (Popper, 1992). Assim, uma teoria não é nunca verdadeira; ela é sempre provisória, a melhor que se tem até o momento. O desenvolvimento da ciência se opera através de "desafios" lançados a uma teoria, ou seja, buscando colocá-la à prova, verificando se ela resiste ao teste da experiência e, eventualmente, abandonando-a em favor de uma outra mais completa.

Essa concepção de ciência é totalmente destituída de aspectos sociais. Ela não leva em conta os aspectos históricos e culturais de produção dos conhecimentos. Contrapondo-se a essa visão aparecem os trabalhos de Thomas Kuhn que introduz a temporalidade nos estudos sobre a ciência.

Segundo Kuhn (1995), existem dois modos distintos de desenvolvimento científico, que ele chama de ciência normal e de revolução. Ele sustenta que a maior parte da atividade científica, que constitui a ciência normal, não consiste em testar as teorias existentes, mas, ao contrário, em desenvolvê-las. A ciência normal trabalha dentro do que Kuhn chama um paradigma. Esse conceito é equivalente a um sistema de crenças, representando uma visão do mundo que inclui o conjunto dos problemas tidos como interessantes, as unidades de análise desses problemas, as ferramentas disponíveis para a busca de soluções e os exemplos, isto é, conjunto de problemas que o paradigma permitiu resolver.

Assim, os adeptos de um paradigma se esforçam, em geral, para desenvolvê-lo sem tentar derrubá-lo. Apenas quando as dificuldades que desafiam o paradigma se acumulam e o número de explicações ad hoc cresce, acontece uma revolução. Aparece então um novo paradigma, radicalmente diferente do anterior, com novos conceitos e novos problemas para serem resolvidos. Segundo Kuhn, o desenvolvimento científico ocorre por acumulação e ruptura.

O debate entre essas duas visões da ciência domina o cenário da epistemologia atual. Entretanto, elas não estão isentas de críticas. Em particular, a ausência completa do indivíduo (o pesquisador) se faz sentir. Uma outra crítica, que amplia essa primeira, diz respeito ao papel dos aspectos sociais nas teorias epistemológicas. Embora Kuhn trate do contexto histórico no estudo da evolução da ciência, o contexto social está estranhamente ausente. Isso acontece porque a epistemologia preocupase fundamentalmente com os produtos da ciência (contexto da prova ou da justificativa) e não com as condições da descoberta científica (contexto da descoberta). São essas condições, as influências sociais, a imaginação científica, as intuições, o raciocínio analógico, que serão privilegiados numa abordagem sociológica do estudo da ciência.

\section{A abordagem sociológica}

$\mathrm{Na}$ abordagem sociológica procura-se compreender como a ciência funciona a partir da maneira como ela é feita e das condições nas quais ela é produzida. Isso implica fazer uma distinção entre a ciência e a pesquisa. A primeira é a ciência feita (o produto), a segunda é a ciência se fazendo (o processo), isto é, a ciência em ação (Latour, 1991). A epistemologia estuda a ciência feita (as ligações internas da lógica das idéias); a sociologia da ciência estuda a ciência que se faz, isto é, a prática da ciência.

Em epistemologia, as entidades de base são abstrações do tipo "teoria" ou "método". Há pouco espaço para os aspectos sociais, que são considerados marginais ou mesmo perturbadores do desenvolvimento da ciência. Bruno Latour apresenta (e critica) o modelo clássico das relações entre ciência e sociedade como uma oposição entre o núcleo duro da ciência e o seu contexto social: "uma ciência será tanto mais exata, mais correta, mais objetiva, quanto mais desligada for das contingências do mundo social" (Latour, 1995, p. 21).

No seu início, a sociologia da ciência tratava muito mais da organização da ciência do que de seus conteúdos. A sociologia clássica da ciência tem em Robert Merton (1977) um de seus autores mais significativos. Adotando uma visão funcionalista da ciência, Merton discutia a institucionalização das normas que orientam a produção de conhecimento "certificado", isto é, daquele que vai se tornar parte do corpo da ciência. A sociologia mertoniana não trata da influência social no conteúdo da ciência, mas na organização da ciência.

Somente em época mais recente (anos 1970) é que a sociologia passou a se interessar pelo conteúdo científico da ciência (pela ciência ela mesma), se destacando das análises anteriores, voltadas principalmente para a ciência enquanto sistema social.

Vários desses estudos sociológicos, que não concedem à ciência um status privilegiado de conhecimento verdadeiro e superior, inscrevem-se na corrente filosófica do relativismo. Como os conhecimentos científicos são considerados como relativos ao contexto no qual foram obtidos, o sucesso de uma 
teoria não pode ser atribuído a sua validade ou veracidade intrínseca. Na realidade, uma teoria não é bem sucedida porque ela é verdadeira, mas ela é verdadeira porque foi bem sucedida. A sociologia da ciência, então, se propõe a explicar a aceitação de uma teoria pela comunidade científica a partir de fatores, sociais ou outros, independentes da validade das teorias, pois essa é apenas uma constatação a posteriori. Daí o interesse dos sociólogos pelas controvérsias científicas, pois elas permitem estudar, dentro do próprio debate, os fatores que decidiram em favor de uma teoria ou outra.

Dentro dessa linha, foi proposta a idéia de redes científicas (Callon, 1988; Latour, 1991). Essa noção se refere a todos os interlocutores e parceiros de um pesquisador, em seu laboratório ou fora dele, que desempenham um papel na definição do conteúdo das pesquisas, na orientação dos programas, na avaliação dos resultados. Trata-se de intermediários de todo tipo - humanos ou não, colaboradores, pessoal administrativo, clientes, mas também documentos de referência, créditos disponíveis para a pesquisa, instrumentos de medida - que intermedeiam o contato do pesquisador com a natureza e a sociedade. A identificação dessas redes, de seus componentes e interligações, auxilia a compreender o processo de criação, difusão e, às vezes, morte dos fatos científicos.

Entretanto, essa abordagem da ciência parece não deixar nenhum espaço para o indivíduo. Embora seja verdade que, em princípio, o relativismo não separa o social e o cognitivo, os fatores externos e internos, "sente-se claramente a forte tendência dos relativistas pelas explicações puramente sociológicas, externas portanto" (Matalon, 1996, p. 135).

Seria interessante investigar o que uma articulação do sociológico e do psicológico poderia trazer de novidade ao estudo da pesquisa, isto é, da ciência enquanto processo de produção de conhecimento.

\section{A contribuição da psicologia social}

Notemos inicialmente que o estudo da ciência a partir da psicologia social encontra-se no cruzamento de duas grandes tendências: os estudos sobre a representação social da ciência pelo público não especialista (a população em geral) e as discussões sociológicas sobre a ciência. Os estudos feitos pelos pesquisadores do LSE (London School of Economics) em Londres, como, por exemplo, Bauer e Schoon (1993), Bauer, Durant e Evans (1994) e Bauer e Gaskell (2002), da EHESS (Ecole de Hautes Etudes en Sciences Sociales) em Paris, por exemplo, Elisabeth Lage (1978, 1993), e da Universidade de Santa Catarina, em Florianópolis, por exemplo Nascimento-Schulze, Fragnani, Carboni, Schucman, Wachelke (2003), são exemplos da primeira tendência; Latour (1991, 1995), Callon (1988) e Matalon (1996), mencionados anteriormente, acompanham mais de perto a segunda.

Observemos em seguida que, contrariamente a uma epistemologia mais ortodoxa, voltada para os estudos das produções científicas terminadas, a sociologia da ciência propõe uma investigação da própria gênese da ciência, dentro dos laboratórios. Trata-se muito mais de um estudo da pesquisa/processo (ciência se fazendo) do que da ciência/produto (ciência feita).
Ora, este ponto de vista justifica plenamente um estudo sobre as representações sociais da pesquisa pelos pesquisadores e, em particular, pelos doutorandos, pesquisadores em formação. São essas representações - como a pesquisa se organiza, para que ela serve, a quem ela serve, qual o espaço da ética dentro da ciência, etc. - que circulam no discurso dos pesquisadores e que formam toda uma visão sobre a ciência e a maneira de praticá-la. Isso é importante principalmente para os doutorandos.

É no quotidiano dos trabalhos de pesquisa de um laboratório que os doutorandos vão tomando contato com facetas desconhecidas da atividade científica: eles encontram questões propriamente cientificas, como a de disputas entre diferentes teorias ou abordagens; questões semi-cientificas, como a necessidade premente de produzir artigos e publicações; questões administrativas inusitadas, como as dificuldades de organização de um congresso ou de edição dos anais; questões de relacionamento pessoal, com o orientador ou a equipe de trabalho; e finalmente questões econômicas, como compra de material e equipamentos, crédito para viagens ou obtenção de bolsas. Essas diversas situações com as quais eles têm contato, ou das quais ouvem falar, terão influência na percepção que eles têm da pesquisa, e poderão transformar (em maior ou menor grau) suas representações sociais.

Entretanto, o doutorando dispõe de uma autonomia relativa no trabalho que desenvolve: cabe a ele fazer a tese e defender o produto de seu trabalho ao final do doutorado. Existem, é claro, várias normas institucionais que definem alguns aspectos de seu trabalho (tempo limitado, provas, normas de confecção do texto da tese) bem como restrições de ordem material (livros, bolsa, equipamentos). No entanto, em uma larga medida, o trabalho de tese é ainda uma construção do doutorando.

Ora, Abric (1994, p. 230) propõe que, em situações em que o ator dispõe de uma certa autonomia em relação às restrições impostas pela situação ou pelas relações de poder, as representações sociais desempenham um papel determinante sobre as práticas sociais. Esse ponto de vista é retomado neste trabalho, com relação à representação social da pesquisa pelos doutorandos, apoiando-se na relativa autonomia de que dispõe o doutorando na construção de seu trabalho de pesquisa.

Chegamos assim à nossa hipótese principal, ou seja, de que a representação que os pesquisadores têm de sua atividade não é influenciada apenas pela própria ciência, mas contém vários elementos extra-cientificos, incluindo representações de senso comum partilhadas com a população em geral e preexistentes ao trabalho de pesquisa, e que essa representação tem uma incidência significativa na maneira como eles exercem essa atividade. Além disso, e esse ponto é essencial, essa representação é socialmente construída e circula na comunicação. Para os doutorandos que constituem nosso grupo de estudo, a representação contribui também para a elaboração de uma identidade social e profissional específica.

A contribuição da psicologia social ao estudo da ciência se dá exatamente nesse nível: considerá-la como atividade humana socialmente construída e estudar as representações daqueles que a praticam. 


\section{Método}

O presente estudo utiliza a entrevista como técnica para obtenção de dados. Essas entrevistas foram submetidas a uma análise de conteúdo informatizada, na qual se utilizou o software de análise ALCESTE, desenvolvido na Universidade de Toulouse, França. A abordagem qualitativa foi empregada nessa etapa de nosso trabalho para captar a complexidade essencial dos fenômenos sociais, dar atenção maior à busca do sentido dado pelos doutorandos a suas ações e palavras, e levar em conta dados lingüísticos, mais ricos, em princípio, do que dados puramente numéricos.

\section{A entrevista}

Como salientam Doise, Clemence e Lorenzi-Cioldi (1992), o estudo das representações sociais repousa sobre o material oferecido pela linguagem. Assim, neste trabalho, nós adotamos a entrevista como técnica privilegiada de coleta de dados. Escolhemos a entrevista semi-diretiva como forma principal de sondagem, pois ela permite uma orientação parcial dos temas a serem abordados no discurso do entrevistado - o que favorece a validade da informação obtida - e oferece, ao mesmo tempo, a oportunidade ao entrevistado de estruturar seu próprio discurso, de maneira original e significativa, o que favorece a confiabilidade da informação recolhida.

Esse tipo de entrevista começa pela proposição de uma questão geral, na qual o tema da pesquisa é anunciado, mas o entrevistador pode orientar a entrevista na direção de certos sub-temas que lhe interessam, caso o entrevistado não os aborde espontaneamente. Nossas entrevistas começavam pela apresentação do tema geral relativo à pesquisa e ao trabalho de tese desenvolvido pelo doutorando (Como se desenvolve um trabalho de pesquisa, em geral, e seu trabalho de tese, em particular?) e, em função do desenvolvimento desse tema, algumas questões eram lançadas para cobrir os eixos principais de nosso estudo: a produção de conhecimentos; as relações pesquisa-sociedade; a pesquisa fundamental e a pesquisa aplicada; as qualidades do pesquisador; a pesquisa para a tese.

\section{Os participantes}

As entrevistas, de duração aproximada de uma hora, foram realizadas com 26 doutorandos, de diversas nacionalidades, buscando cobrir todos os anos da formação (do primeiro ano, ao pós-doutorado). Todos desenvolviam trabalhos na área de ciências exatas (13 engenheiros, oito físicos e cinco matemáticos, especialistas em computação), em laboratórios da região de Toulouse, França. Os doutorandos foram contatados de maneira informal, por outros estudantes, colegas de formação, e foram selecionados de maneira a garantir a maior diversidade possível em termos de ano de doutorado, laboratório de origem, experiência profissional e percurso acadêmico.

\section{O tratamento dos dados}

Para a interpretação das entrevistas nós utilizamos a análise de conteúdo, que é um instrumento de análise das comunicações. Trata-se de uma técnica que procura explorar a riqueza do discurso do indivíduo sem se perder na sua complexidade e sem se limitar unicamente à intuição do pesquisador. Dentre as diversas formas que a análise de conteúdo pode assumir (Bardin, 1991; Quivy \& Van Campenhoudt, 1988), nós adotamos a análise por categorias e a análise de ocorrências simultâneas.

A análise por categorias é uma das formas mais antigas e mais utilizadas de análise de conteúdo. Ela funciona a partir de uma segmentação do texto em unidades, seguida de uma classificação dessas unidades em categorias, definidas a priori a partir de uma análise teórica ou induzidas pelo próprio texto. $\mathrm{Na}$ prática, a classificação por temas representa a variante mais popular dessa técnica. A análise de ocorrências simultâneas procura estudar as presenças (ou as ausências anormais) de dois ou mais elementos em uma mesma unidade significante do texto, isto é, em um fragmento de texto previamente definido. A freqüência das ocorrências é indicativa da associação ou dissociação dos elementos no discurso do entrevistado.

A adoção da análise por categorias, na forma de uma análise por temas, é uma conseqüência natural da estrutura de nossas entrevistas, que estão orientadas na direção de sub-temas mais ou menos específicos e diferenciados. A análise de ocorrências simultâneas é a técnica utilizada pelo programa ALCESTE na análise de dados textuais. Essa dupla estratégia nos permitiu o estudo das entrevistas em dois níveis: uma análise global, que trata do universo discursivo dos doutorandos e que delimita os grandes temas que ele contém, e uma análise local, que permite estudar temas específicos do trabalho.

Assim, a primeira análise do corpus das entrevistas deu origem a três grandes classes de discurso, com um total de 1428 unidades de contexto elementares (ou u.c.e. - ver discussão do programa ALCESTE mais adiante): uma primeira classe sobre o impacto cultural de estudar em um outro país (centrada principalmente sobre a questão identitária - individual, social e profissional), compreendendo $30 \%$ das u.c.e.; uma segunda classe específica sobre a pesquisa (em geral), correspondendo a $25 \%$ das u.c.e.; e uma terceira classe sobre o trabalho de tese, as relações com o orientador e a formação científica de um modo geral, correspondendo a $45 \%$ das u.c.e..

É a análise local do sub-tema pesquisa, objeto da classe II, que nós propomos nesse trabalho. Dessa forma, os trechos das entrevistas originais que correspondiam ao tema dessa classe foram reagrupados e submetidos a uma nova análise pelo programa ALCESTE, gerando um refinamento das classes de discurso. A discussão dos resultados dessa segunda análise é apresentada mais adiante.

\section{O programa ALCESTE}

O programa ALCESTE (Analyse Lexicale par Context d'un Ensemble de Segments de TExte), desenvolvido na Universidade de Toulouse II, França, por Max Reinert (1990), realiza uma classificação do texto estudado em função das ocorrências simultâneas do seu vocabulário. A idéia é, a partir da distribuição do vocabulário do texto, construir mundos lexicais, que são conjuntos de proposições estatisticamente "próximas".

O programa procura dividir o conteúdo das entrevistas em unidades de contexto que correspondem, segundo Bardin (1991), "ao segmento de mensagem cujo tamanho é ótimo para definir a significação exata da unidade de registro" (p. 138); em nosso caso essa unidade de contexto é o que Reinert $(1990,1993)$ chama de 
enunciado. Ele corresponderia a uma proposição sobre o mundo, do ponto de vista do sujeito que a enuncia. A operacionalização desse conceito (que é, como admite o próprio Reinert, de difícil apreensão) é feita por meio das chamadas unidades de contexto elementares (u.c.e.).

Para definir essas unidades, o programa utiliza certas estratégias baseadas em restrições gerais às quais elas devem obedecer. Duas restrições são exploradas: a pontuação e o tamanho da unidade. Sempre que possível, uma u.c.e. deve corresponder a um final de frase e seu comprimento não deve ultrapassar duas ou três linhas. Essa divisão é necessariamente arbitrária, mas ela pode ser variada de modo a se verificar a estabilidade dos resultados obtidos. Entende-se aqui estabilidade como independência dos resultados em relação às variações introduzidas na divisão do texto.

Na construção das u.c.e., são eliminadas preposições, conjunções, artigos (as chamadas palavras-instrumento) e desinências de conjugações, guardando-se apenas os lexemas, isto é, as unidades mínimas com um significado autônomo das palavras cheias (verbos e nomes, essencialmente).

Uma análise feita com ALCESTE comporta, esquematicamente, cinco etapas (Reinert, 1990, p. 33):

(1) Definição das unidades de contexto elementares. Essa etapa corresponde à divisão do texto mencionada anteriormente. Nessa etapa, também, o programa efetua certas operações simples, como a supressão de acentos e maiúsculas e o reconhecimento das locuções mais usuais. As unidades mínimas que compõem essa divisão são chamadas de unidades de contexto elementares (u.c.e.).

(2) Busca das formas reduzidas. Uma mesma palavra pode apresentar-se sob diversas formas em função das marcas de plural, conjugação, etc. O programa opera, nessa etapa, uma redução dessas formas múltiplas a uma forma de base, que será utilizada na seqüência da análise. As formas reduzidas representam a operacionalização dos lexemas. Elas constituem as unidades de registro. $\mathrm{O}$ contexto da unidade de registro é a u.c.e.

(3) Definição das tabelas de dados. Nessa etapa são criadas tabelas disjuntivas completas (tabelas lógicas, codificadas com " 0 " ou " 1 "), que cruzam, nas linhas as u.c.e. e, nas colunas, as formas reduzidas. Essas tabelas são em seguida usadas na análise de ocorrências simultâneas.

(4) Busca das classes. A partir da tabela lógica já definida, o programa efetua uma Classificação Hierárquica Descendente das unidades analisadas. Como resultado dessa operação, aparecem as classes de discurso, ou mundos lexicais. O dendograma da classificação permite visualizar a organização das formas reduzidas na classe.

(5) Arquivos de auxílio à interpretação. Terminada a análise, o programa cria diversos arquivos de auxílio à interpretação dos resultados obtidos. Entre eles, o arquivo de descrição do perfil das classes (lista das palavras contidas na classe), o arquivo das u.c.e. das classes (lista das u.c.e. de cada classe, o que permite posicionar as palavras no contexto original) e também o arquivo do anti-perfil das classes (lista das palavras pouco ligadas a uma classe). Nas versões mais recentes do programa, o arquivo do anti-perfil foi substituído pela lista das palavras ausentes (absences significatives) associadas a uma classe. Finalmente, uma Análise Fatorial de Correspondências permite visualizar as relações entre as classes.

\section{Resultados e Discussão}

A classe referente ao sub-tema pesquisa é composta de $25 \%$ do total das u.c.e.(325 unidades) obtidas no discurso dos doutorandos. Os resultados das análises realizadas nessa classe nos mostraram que os aspectos fundamentais do discurso dos doutorandos estão ligados às relações entre a pesquisa fundamental e a pesquisa aplicada, e à maneira como se dá, nessas duas formas de pesquisa, a produção e utilização dos conhecimentos.

A análise feita sobre os discursos relativos ao sub-tema pesquisa revela a existência de três eixos temáticos (três classes de discurso): (1) as relações entre pesquisa fundamental e pesquisa aplicada; (2) a produção e a utilização do conhecimento e (3) a atividade do pesquisador. No interior da primeira classe aparece a tensão entre as duas modalidades da pesquisa, mas elas são sempre discutidas em conjunto pelos doutorandos. A segunda classe (produção e uso do conhecimento) relaciona-se com a utilidade do conhecimento produzido e com as restrições impostas ao conteúdo da pesquisa por agentes extra-científicos. A terceira classe, que não será aprofundada neste texto, referese às características da atividade do pesquisador e a uma visão idealizada de suas qualidades.

Ao longo das análises, serão apresentados trechos do discurso dos doutorandos que ilustram os pontos destacados. Optou-se por apresentar o discurso original, e não as u.c.e's correspondentes, para maior fluidez do texto. As unidades de contexto foram expandidas, buscando-se no discurso original o contexto onde se encontravam.

\section{Classe 1: pesquisa fundamental e pesquisa aplicada}

Em geral, as representações da pesquisa são ligadas a julgamentos de valor, como útil/inútil, associadas a mecanismos de compensação. Assim, uma pesquisa considerada inútil (situação normalmente associada à pesquisa fundamental) é vista como mais nobre, como "verdadeira pesquisa desinteressada"; uma pesquisa considerada como mais "útil" (em geral o caso da pesquisa aplicada) será vista como menos autônoma, mais dirigida por interesses "extra-científicos". Essa oposição, apresentada de maneira muito esquemática, é muito mais complexa e sutil. Na realidade, várias pesquisas são apresentadas simultaneamente como fundamentais e aplicadas, na fronteira entre as duas áreas.

A oposição entre esses dois tipos de pesquisa não é explicitamente endossada pelos doutorandos. Eles acreditam que uma depende da outra, "sem a pesquisa fundamental nenhuma pesquisa tem sentido" (Entrevistado 1), e, mesmo os doutorandos que dizem não ter interesse em fazer pesquisa fundamental, consideram que é necessário apoiá-la. A separação, quando ela é mencionada, deve-se à abordagem científica e às particularidades de uma área específica. Ou então essa separação é exterior à pesquisa.

Assim, segundo os doutorandos, a separação pesquisa fundamental/aplicada, não se traduz por uma oposição entre elas ou pela superioridade de uma em relação à outra. Essa 
separação significa simplesmente que as preocupações, nas duas modalidades, não são as mesmas. Por outro lado, eles são muito conscientes de que existe uma tendência - exterior ao meio científico, isto é, nos políticos, nos industriais, no público em geral - a valorizar os resultados mais imediatos, um retorno a mais curto prazo do investimento feito. Essa tendência afeta principalmente a pesquisa fundamental, em que os resultados são menos visíveis e de mais longo período de maturação. Esse raciocínio explica a defesa que eles fazem da pesquisa fundamental: eles a consideram menos apta a responder a argumentos de ordem econômica ou utilitária.

É necessário convencer os políticos, convencer os organismos de fomento etc., com um discurso bem feito. [...] Um pesquisador deve buscar o dinheiro para sobreviver. Isso não faz parte das funções nobres, mas faz parte das coisas que ele tem que fazer. (Entrevistado 4)

Essa atitude é justificada pelos trabalhos que avaliam a atitude e o interesse do público em geral em relação à ciência: uma pesquisa imediatamente utilizável sempre obtém apoio, enquanto que a pesquisa fundamental (basic research) perde o crédito junto ao público (Bauer et al., 1994; esse estudo diz respeito à população inglesa). Dessa maneira, os doutorandos buscam argumentos para defendê-la:

Se nós bloquearmos a pesquisa fundamental dizendo: a gente coloca todos os meios disponíveis na indústria ou na pesquisa a curto prazo, isto quer dizer que, a longo prazo, nós não teremos amadurecido, não haverá mais evolução possível, conhecimentos verdadeiros. (Entrevistado 2)

Esse tipo de defesa não parece constituir um elemento necessário à pesquisa aplicada.

O doutorandos evocam essas duas categorias de pesquisa com as reduções já mencionadas. Eles estabelecem relações de complementaridade entre a pesquisa fundamental e a aplicada e reconhecem que, em alguns ambientes extra-científicos, aparecem oposições entre ambas. Curiosamente, eles não estabelecem ligações entre esse tema e o próprio trabalho de tese que eles desenvolvem. Eles falam da pesquisa em termos gerais e dão exemplos afastados do próprio trabalho. Tudo se passa como se houvesse uma separação entre a tese e a pesquisa.

\section{A pesquisa aplicada}

A pesquisa aplicada é representada como ligada à indústria, às restrições econômicas e à falta de liberdade. Ela é feita para resolver problemas e modificar a natureza. Financiada pelos industriais, ela está ligada à tecnologia e às necessidades de uma área específica. Essa regulação da pesquisa por instâncias econômicas acaba gerando uma confusão entre a pesquisa e seus produtos: "eu prefiro a pesquisa de resultados" (Entrevistado 3), entendendo-se aí um resultado-produto, imediatamente utilizável. Existe nesse caso uma forte objetivação de um objeto de representação: se é relativo à prática, é pesquisa aplicada; se é pesquisa aplicada, é tecnologia; se é tecnologia, é próprio à indústria.

O esquema apresentado no Figura 1 sintetiza essas idéias:

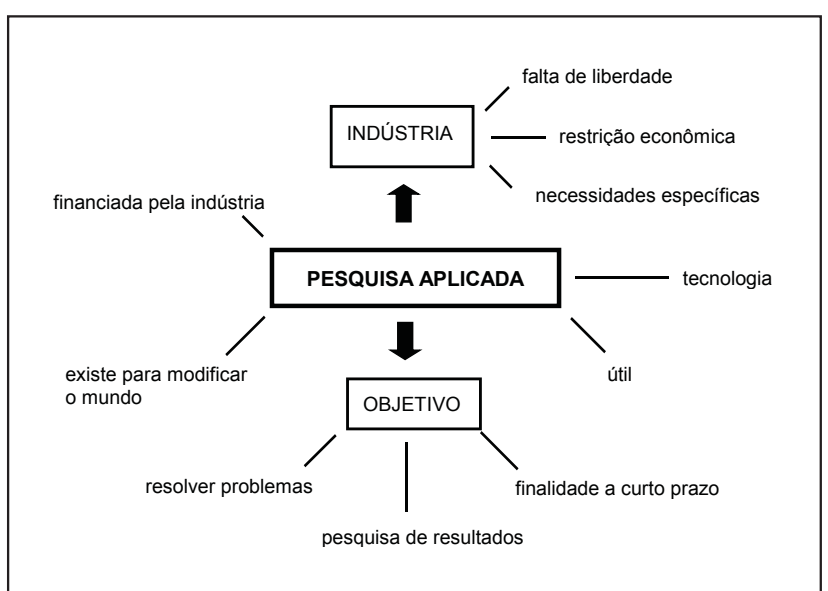

Figura 1. Estrutura da classe de discurso associada à pesquisa aplicada.

\section{A pesquisa fundamental}

A pesquisa fundamental evoca nos doutorandos muito mais conteúdos representacionais. Existe, inicialmente, o aspecto mítico, ligado aos grandes pólos de atração da ciência, as grandes descobertas, as fórmulas, as teorias e a associação com as áreas apontadas como modelo de ciência: a física e a matemática. Nota-se, em seguida, uma grande atenção com respeito às aquisições científicas passadas, sugerindo uma visão da ciência como produto acabado. Evoca-se a pesquisa, mas fala-se da ciência (conforme a já mencionada distinção de B. Latour entre ciência e pesquisa).

Sempre associada às grandes descobertas, ela guarda esse lado incerto e espetacular, como indicado nas falas dos doutorandos:

A pesquisa fundamental, para mim, é como um jogo de pôquer; um cara que é super teórico e, de repente, se a coisa funciona, isso pode ter repercussões enormes (Entrevistado 6)

Quando a gente faz pesquisa fundamental, um dia se está diante da folha e, de repente... (Entrevistado 7)

A pesquisa fundamental é vista como desligada da realidade (entendida como realidade aparente, quotidiana) sem apresentar um retorno imediato para a sociedade. Seu objetivo é mais nobre: fazer avançar a ciência e a compreensão do mundo. Ela é tipicamente desinteressada, no sentido de não estar ligada ao dinheiro, embora necessite de grandes financiamentos para se desenvolver.

Essa neutralidade implicada pelo "desinteresse" não se estende ao plano ético: "eu não aceito ciência sem ética" (Entrevistado 8). Nós podemos ver julgamentos de valor aparecerem sob a forma de uma "boa" e de uma "má" ciência. O exemplo típico da boa pesquisa fundamental é a pesquisa médica: "mesmo desligada da sociedade civil, faz anos que os cientistas fazem pesquisas sobre AIDS, eles receberam muito dinheiro e agora eles apresentam resultados realmente animadores, agora realmente a palavra útil ganha sentido" (Entrevistado 9).

O protótipo da má pesquisa é a bomba atômica e, por exten- 
são, as pesquisas em projetos militares: "[não posso] trabalhar diretamente num projeto mórbido, por exemplo, um projeto militar" (Entrevistado 10).

Essas representações da pesquisa coincidem com aquelas recolhidas por E. Lage (1978) junto a estudantes do Lycée na França (equivalente ao ensino médio): "trata-se de um discurso humanitário e individualista, colocando a medicina como definição de progresso científico e condenando o progresso destruidor simbolizado pela energia atômica e pela pesquisa militar" (Lage, 1978, p. 125).

Essa é essencialmente a mesma conclusão a que chegam Bauer e colaboradores (1994), estudando as representações da ciência na população européia em geral. Essa correspondência mostra mais uma vez que os doutorandos partilham representações sociais de outros grupos, não diretamente ligados à pesquisa.

Podemos também observar ancoragens psicológicas na construção dessas representações da pesquisa. De fato, valores e crenças muito gerais (como a idéia de bem e de mal, da responsabilidade do homem por seus atos) formam uma base de conceitos familiares que dão sentido ao objeto de representação (no caso a pesquisa).

O esquema apresentado na Figura 2 sintetiza os conteúdos, evocados pelos doutorandos, que se ligam à pesquisa fundamental. Nós podemos notar um conjunto de características (ausência de aplicação, puramente intelectual) que definem a pesquisa fundamental e que estão presentes em outros grupos dentro da sociedade. Podemos ver, também, alguns pontos par-

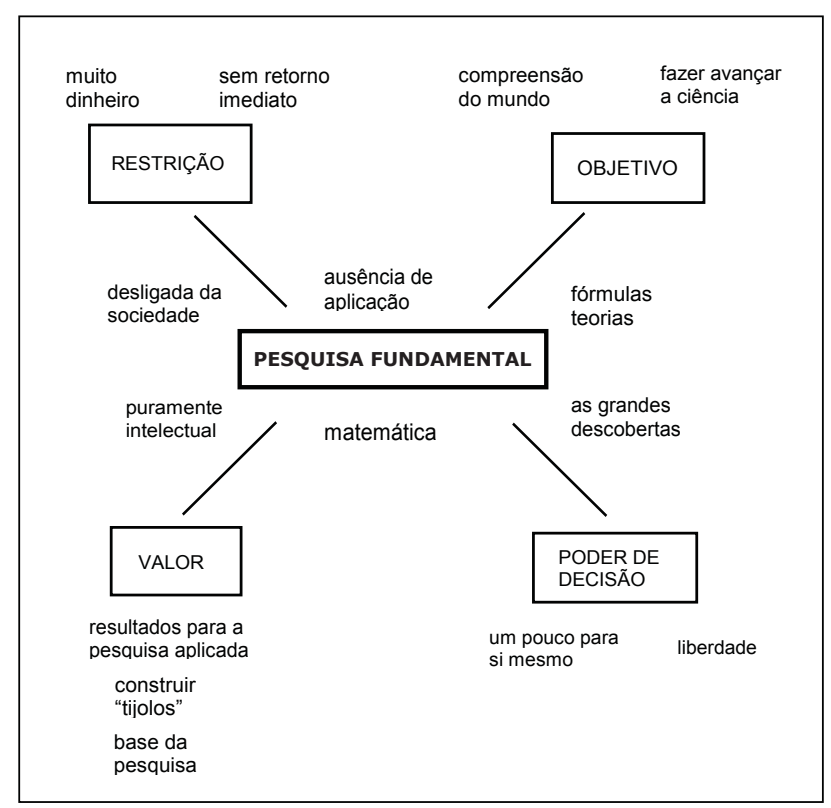

Figura 2. Estrutura da classe de discurso associada à pesquisa fundamental.

ticulares, próprios ao grupo dos doutorandos, que especificam a representação.

\section{Classe 2: Produção e uso do conhecimento}

Discutindo os conhecimentos produzidos, os doutorandos posicionam-se imediatamente do lado de sua utilidade social:
"Eu vejo vantagens para a sociedade somente se a produção de conhecimento estiver dirigida para as necessidades da sociedade. [...] A ciência deve sempre servir à melhoria das condições de vida" (Entrevistado 13).

Entretanto, os problemas de financiamento e as restrições econômicas que o setor produtivo (empresários, clientes) podem impor à pesquisa estão bem presentes no espírito dos doutorandos: "a pesquisa não serve para nada, é preciso produzir, produzir, produzir para ganhar cada vez mais dinheiro" (Entrevistado 4). A pesquisa aqui (essa que "não serve para nada") corresponde a uma pesquisa não-aplicada. "Produzir para ganhar cada vez mais dinheiro", aponta na direção das aplicações imediatas da pesquisa na produção.

O fator econômico impõe também uma outra orientação à escolha dos temas de pesquisa: "Se você quer trabalhar num assunto que te interessa, então trabalhe no MacDonald's para financiar a tua pesquisa, porque para mim, isso não me interessa" (Entrevistado 5).

Essas observações apontam para os compromissos (econômicos e outros) que contribuem para dar forma à pesquisa. A existência desses compromissos está presente nos discursos analisados. São mencionadas também as redes científicas, no sentido indicado anteriormente (Callon, 1988; Latour, 1991), construídas pelos laboratórios de pesquisa.

Os pesquisadores aqui estabeleceram o caminho para ter acesso aos congresso, publicar os trabalhos nas boas revistas. [...] Por exemplo, conhecer as pessoas do comitê editorial, do comitê de organização do congresso. assim, quando se envia um artigo, ele é aceito, o revisor diz, eu conheço essa pessoa. (Entrevistado 1)

Há também as outras redes, que apontam para os "não-cientistas" (empresários ou outros clientes de um modo geral) que intervêm e servem de interlocutores no processo de constituição do conteúdo da pesquisa. Percebe-se a existência dessas outras redes, mas elas são interpretadas como uma distorção do sistema científico e não como uma de suas características.

Uma grande parte da pesquisa atual é financiada pelas empresas que têm interesses próprios que não representam os da sociedade. Elas estão interessadas em criar novas necessidades, em desenvolver monopólios de produção, em enriquecimento. Eu tenho dúvidas se é este conhecimento que a sociedade quer hoje em dia. (Entrevistado 1)

\section{Classe 3: Atividade do pesquisador}

A terceira classe é bastante heterogênea, no que diz respeito aos temas abordados, e não será discutida aqui. Ela indica, principalmente, as qualidades do professor-orientador-pesquisador, salientando características individuais ligadas ao trabalho de ensino e pesquisa.

Assim, a representação social que os doutorandos têm da pesquisa incorpora um modelo de pesquisa (definida como processo de produção de conhecimentos científicos) que é estruturado pela oposição entre o núcleo da pesquisa e seu contexto. As extensões representadas pelas redes científicas são consideradas como interferências ou distorções do sistema (pressões econô- 
micas e políticas). As relações com a sociedade são vistas como muito importantes, mas são ligadas imediatamente a questões éticas e à responsabilidade do pesquisador. Dessa forma, essas questões são mantidas no nível do pesquisador, preservando-se a integridade do núcleo.

\section{Considerações Finais}

A análise dos resultados obtidos revela a ação dos dois processos de base responsáveis pela gênese de uma representação social: a objetivação e a ancoragem. As simplificações, as reduções e as transformações (algumas ingênuas, outras muito mais elaboradas) realizadas na apropriação da pesquisa enquanto objeto de representação social, caracterizam o processo de objetivação. A restrição da pesquisa aplicada a objetivos industriais ou a idealização da pesquisa fundamental como busca dos grandes mistérios do universo são exemplos desse processo. Podemos notar que a redução feita nesse caso tende a opor a pesquisa aplicada à pesquisa fundamental. Os doutorandos, como vimos, recusam essa oposição, mas insistem na defesa da pesquisa fundamental, o que mostra que eles estão bem conscientes da distância entre esses dois tipos de atividade científica e do fato que a pesquisa fundamental é mais sujeita à crítica social.

A integração da pesquisa a categorias estabelecidas e o recurso ao uso de estereótipos indicam a ancoragem da idéia de pesquisa em realidades preexistentes, na rede de representações que o indivíduo já construiu. As considerações éticas sobre os produtos da pesquisa, como a "boa" e a "má" ciência, é um exemplo desse processo de ancoragem.

A pesquisa leva, efetivamente, à descoberta de coisas novas e produz conhecimento. Mas este fato é imediatamente analisado pelos doutorandos em termos éticos, em termos da utilidade dessas descobertas para a sociedade, o que mobiliza o sistema de valores do indivíduo. Essa categorização feita a partir de considerações éticas (a medicina como boa ciência; a bomba atômica como má ciência) está baseada em representações já existentes, e que circulam na sociedade, como mostram as pesquisas de E. Lage (1978) sobre a representação dos estudantes de nível médio.

A representação social dos doutorando com relação à pesquisa apresenta certas especificidades, produzidas no próprio exercício da atividade de pesquisa. Assim, a idéia de redes de pesquisa, por exemplo, é desenvolvida pelos doutorandos, que vêem essas estruturas se formar e evoluir nos laboratórios e nas equipes de pesquisa, mas ela não é comum fora do meio científico. Como vimos, essa noção diz respeito aos interlocutores e parceiros de um pesquisador, que desempenham um papel na definição das pesquisas. Os doutorandos percebem a existência dessas redes e as classificam em duas categorias: redes em que somente intervêm outros pesquisadores e laboratórios de pesquisa, consideradas como positivas; e redes mais gerais, nas quais os "não-cientistas" estão presentes (industriais, clientes, etc.), que são vistas como interferências ou distorções do sistema. Essas características não são compartilhadas por outros grupos, como indicado nos estudos sobre a representação da pesquisa pelo público em geral (Bauer et al., 1994; Bauer \& Schoon, 1993).

Essa especificação das representações não está presente nas representações da população em geral. Ela deve, portanto, ser fruto de novas informações adquiridas pelos doutorandos durante sua trajetória científica, o que inclui o trabalho de tese. Pode-se imaginar, então, que à medida que a informação aumenta, o objeto torna-se mais definido, a ponto de não mais poder ser considerado como um objeto de representação, mas como conhecimento científico. Nesse momento, o doutorando teria um conhecimento completo de todos os aspectos do objeto. $\mathrm{Na}$ realidade, ocorre o fenômeno inverso. Essas informações abrem novas perspectivas e outros aspectos do objeto são delineados: os contratos, os comitês de revisão das revistas, as redes científicas. Assim, ao invés de se tornar mais claro e preciso, o objeto cresce em significação e torna-se ainda mais difuso e polimorfo. Tratase de um fenômeno bem conhecido: quanto mais um assunto é estudado, mais ele se torna complexo e mais extensas se tornam as zonas difusas do conhecimento.

\section{Referências}

Abric, J.-C. (1994). Pratiques sociales et représentations. Paris: Presses Universitaires de France.

Bardin, L. (1991). L'analyse de contenu (60 $0^{\mathrm{a}}$ ed.). Paris: Presses Universitaires de France.

Barreau, H. (1995). L'Epistémologie (3 $3^{\underline{a}}$ ed.). Paris: Presses Universitaires de France.

Bauer, M., Durant, J., \& Evans, G. (1994). European public perceptions of science. International Journal of Public Opinion Research, 6(2), 163-186.

Bauer, M. W., \& Gaskell, G. (Orgs.). (2002). Biotechnology: the making of a global controversy. Cambridge: Cambridge University Press.

Bauer, M., \& Schoon, I. (1993). Mapping variety in public understanding of science. Public Understanding of Science, 2, 141-155.

Callon, M. (Org.). (1988). La science et ses réseaux. Paris: La Découverte.

Doise, W. (1990). Les représentations sociales. In R. Ghiglione, C. Bonnet, \& J.-F. Richard (Orgs.), Traité de psychologie cognitive (v. 3, pp. 111-174). Paris: Dunod.

Doise, W. (1992). L'ancrage dans les études sur les représentations sociales. Bulletin de Psychologie, 45(405), 189-195.

Doise, W., Clemence, A., \& Lorenzi-Cioldi, F. (1992). Représentations sociales et analyse de données. Grenoble: Presses Universitaires de Grenoble.

Jodelet, D. (1992). Représentation sociale: phénomènes, concept et théorie. In S. Moscovici (Org.), La psychologie sociale (pp. 357-389). Paris: Presses Universitaires de France.

Kuhn, T. (1995). A estrutura das revoluções científicas. São Paulo: Perspectiva.

Lage, E. (1978). Les représentations sociales du métier de chercheur dans la jeunesse. Rapport scientifique de l'Action Thématique Programmée du C.N.R.S. Contrat C.N.R.S. n ${ }^{\circ} 2156$.

Lage, E. (1993). Lycéens et pratiques scientifiques. Comment les sciences deviennent une passion. Paris: L'Harmattan.

Latour, B. (1991). La science en action. Paris: La Découverte.

Latour, B. (1995). Le métier de chercheur: regard d'un anthropologue. Paris: Institut National de la Recherche Agronomique.

Matalon, B. (1996). La construction de la science. De l'épistémologie à la sociologie de la connaissance scientifique. Lausanne: Delachaux et Niestlé.

Merton, R. K. (1977). La Sociología de la ciencia. Investigaciones teóricas y empíricas. Madrid: Alianza.

Nascimento-Schulze, C. M., Fragnani, E., Carboni, L. R., Schucman, L. V., \& Wachelke, J. F. R. (2003). Representações sociais de ciência e tecnologia e alfabetização científica: um estudo com professores de ciência do ensino médio. In A. Arruda, D. Jodelet, M. C. Madeira, C. M. Nascimento-Schulze, 
\& C. P. Sá (Orgs.), III Jornada Internacional sobre Representações Sociais [CD-ROM]. Rio de Janeiro: Universidade Estadual do Rio de Janeiro.

Popper, K. (1992). A lógica da pesquisa científica. São Paulo: Pensamento Cultrix.

Quivy, R., \& Van Campenhoudt, L. (1988). Manuel de recherche en sciences sociales. Paris: Dunod.

Reinert, M. (1990). ALCESTE - Une méthodologie d'analyse de données textuel- les et une application: Aurélia de Gérard de Nerval. Bulletin de Méthodologie Sociologique, 26, 24-54.

Reinert, M. (1993). Les «mondes lexicaux» et leur «logique» à travers l'analyse statistique d'un corpus de récits de cauchemars. Langage et Société, 66, 5-39.

Rouquette, M.-L. (1994). Sur la connaissance des masses. Grenoble: Presses Universitaires de Grenoble.

Edna Maria Querido de Oliveira Chamon, doutora em Psicologia Social pela Université de Toulouse II - Le Mirail (Toulouse, França), é professora assistente doutora no Departamento de Economia, Contabilidade e Administração, Universidade de Taubaté. Endereço para correspondência: Av. Cidade Jardim, 2700 apto. 14B (Bosque dos Eucaliptos); São José dos Campos, SP; CEP 12233-002. Tel.: (12) 3916-6294. E-mail: edna.chamon@gmail.com 